\title{
PERSPECTIVES
}

OPINION

\section{Signal processing and transduction in plant cells: the end of the beginning?}

\author{
Simon Gilroy and Anthony Trewavas
}

Plants have a very different lifestyle to animals, and one might expect that unique molecules and processes would underpin plant-cell signal transduction. But, with a few notable exceptions, the list is remarkably familiar and could have been constructed from animal studies. Wherein, then, does lifestyle specificity emerge?

Plants and animals have solved the problems of being multicellular in different ways. Eukaryotic photosynthesis evolved some 2,000 million years ago in the oceans. The ubiquity of light over the surface of the globe is thought to have been responsible for a major evolutionary decision by the primordial plant eukaryotic cell; to remain sessile and, as a consequence, to tolerateinevitable predation ${ }^{1,2}$. When plantsinvaded theland, they found the supply and distribution of water, minerals and light much more variable than in the oceans. Among the primary advances made on land werean elaboration of tip branching and the evolution of a differentiated modular structure. Themoduleelements - leaves, buds (dormant meristems), flowers, abscission zones and branch rootsare reiterated many times during development, as aretheir signal-transduction capacities. Such modularity ensures that predation and environmental damage are minimized because some modules usually survive to regeneratetheindividual.

In general, tissue and cell functional specialization is minimized in plants to limit fatal predatory damage. However, somedistribution of functions among different cells is required; for example, the specialized cellular structure of the plant vascular system precludes its direct role in photosynthesis. But most plant cellscan sensenearly all thesignals to which the individual plant responds. Owing to their very different physical environments, however, there are some differences between signals serceived by the root compared with the shoot. How, then, can a plant cell process these myriad signals through to an appropriate response? Herewe emphasizethestructural and spatial characteristics of plant signal transduction, and conclude that organization emerges from the interrelationships of specific components.

\section{Exploitation of growth resources}

The growing shoot can accurately perceive gradients of light, and reflected light from leaves is used to detect the position of neighbours ${ }^{3}$. A three-dimensional image is constructed by the shoot, and growth (and leaf angle) is redirected if necessary to optimize light capture. Each shoot cell acts likean indi-

\section{Box 1 | Single cells can sense fine gradients} swimming activity ${ }^{71}$. vidual ommatidium of the insect eye. Below ground, recent observations have shown ${ }^{4}$ that plants prefer patchily distributed minerals in the soil. Remarkably, the plant can sensethe volume of the patch, maximizegrowth when an optimal volumeis sensed and perceivethe steepness of the gradient across the patch boundary. How thesesoil variables are perceived is not understood ${ }^{4}$. But single plant cells can sense very slight gradients of many environmental factors (BOX 1).

Perception of these important plant resources takes place within the context of an environment that changes from minute to minute. At least 17 environmental variables are sensed (FIG. 1), and each can modify the response to the others ${ }^{5}$. A complex array of external information is therefore either summed or integrated, whereas between other groups of variables, synergistic interactions are common ${ }^{6-8}$

"What is required of plantcell signal-transduction studies... is to account for the capacity for 'intelligent' decision-making; computation of the right choice between close alternatives."

The classic example of fine sensing is the zygote of the marine alga Fucus. This single cell can respond to remarkably slight gradients in temperature, osmotic pressure, light, $\mathrm{pH}$, minerals $\left(\mathrm{K}^{+}, \mathrm{Ca}^{2+}\right)$, solution flow, electrical fields, other chemicals, gases and probably gravity, and direct the orientation of growth accordingly many hours later ${ }^{69}$. These gradients usually have a narrow time window in which they are sensed by the single cell, although in a population of zygotes this window is stochastically distributed around a mean value of several hours. By contrast, the sperm entry site can be remembered for at least a day and be used to specify the direction of growth if no other cues have been detected ${ }^{70}$. A similar remarkable sensitivity to signal gradients is shown by single-celled euglenoids, which can sense their own cytoplasmic weight and modify 


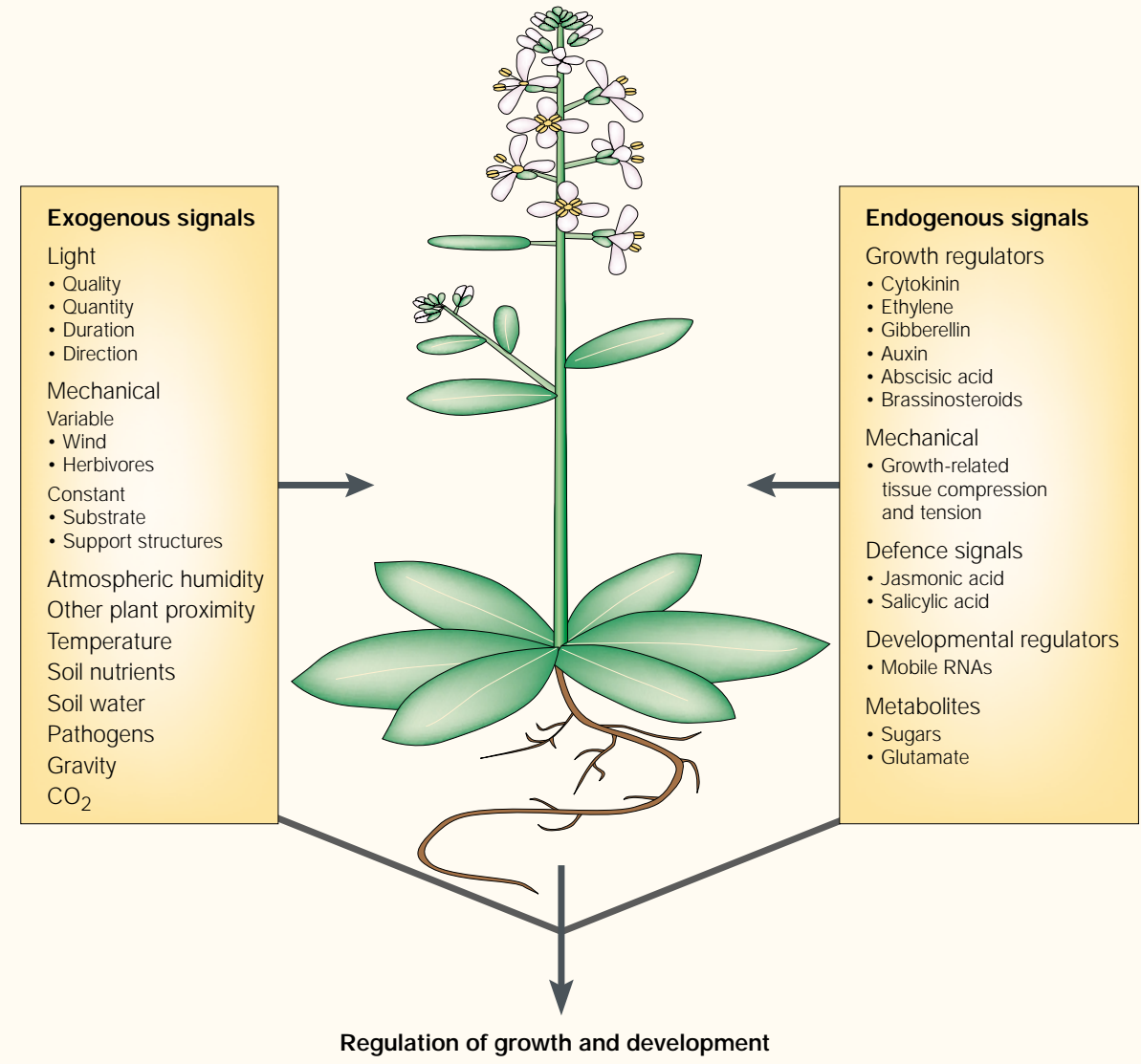

Figure 1 A wide range of disparate external and internal signals is monitored by plants and used to compute appropriate developmental responses. The molecular elements of the plant sensory apparatus and signal-transduction systems can integrate these signals and reach a finely balanced decision as to how to grow and develop to most successfully survive and exploit the environment. As plant responses are generally irreversible growth responses, these signalling systems must compute each developmental decision with extreme care.

Decisions about exploitation of basic nutrient resources can be made by plants before any nutritional benefit is derived. Dodder, a parasitic plant, can sensethelevel of circulating nutrients when it first touches a putative host ${ }^{9,10}$. Within onehour, it 'decides' whether it is worth initiating a developmental programme, which involves shoot-coiling around the host and the formation of haustoria several days later. Rejection of the putative host isfrequent. Oncehaustoria penetratethe host vascular system, nutrients are gained and used for growth. Remarkably, thenumber of coils of the parasite around the host stem reflects with someaccuracy the nutrients in thehost and the likely subsequent return in growth resources. What is required of plantcell signal-transduction studies, then, is to account for the capacity for 'intelligent' decision-making; computation of the right choice between close alternatives.

To exploit patchily distributed environmental resources, dormant meristems can be activated, and individual growing meristems on a singleplant often show striking degrees of independence in growth and signal response. contiguous wall. Because the cytoplasm contains a turgor pressure of about eight atmospheres, compression and tension gradients are common. Nodal points of tension/compression can be expected to elicit changes in development ${ }^{12}$. Such mechanical signals can act as specific morphogens $s^{13}$ and can contribute to the polarized nature of growth and development. Proteinsthat alter themechanical characteristics of the cell wall, such as the recently described expansins $5^{14,15}$, might there foreact as plant-specific developmental regulators. M echanical sensing by higher plants is extremely sensitive, and only slight movement or touch is necessary to induceimme diate responses in cytoplasmic calcium ${ }^{16}$.

The developmental production of successivemodules can also programme changes in signal sensing. During cereal root development, for instance, the lateral roots grow horizontally at first, only later assuming a characteristic vertical direction ${ }^{17}$. Successiveroots become progressively more vertical with respect to gravity, leading to a network of roots that efficiently mines the local soil around thestem.

\section{Phenotypic plasticity}

Because plantsusually havelittlechoice over their immediate growth environment, an ability to modify development to cope with an environment of enormous variability is believed to increase fitness. Phenotypic plasticity - that is, the capability of a single genotype to generatemany phenotypes - is a pronounced and unusual characteristic of plant development ${ }^{1}$. It is al so a crucial feature of plant-cell signal transduction. Specific phenotypic adaptations in morphology, physiology, anatomy, development, reproductive timing, breeding systems and offspring developmental patterns haveall often been observed ${ }^{18}$. Enormous variability in module numbers is common. One view is that a direct coupling of signal transduction to gene expression regulates plasticity. However, the mechanism might not be straightforward and epigenetic processes or even cell individuality, as we indicatelater, might becrucial to theresponse.

Some aspects of development and morphology arestrongly resistant to environmental variation. Numerous complex feedback controls must therefore be operative, but detection of theseis clearly in itsinfancy ${ }^{19,20}$. Furthermore, redundancy in control elements will help strengthen reliability in theface of environmental disruption. Redundancy was an early control featureintroduced into computer design to ensure reliable performance. Polyploidy seems to havehad an important 
PER S PECT IVES

rolein genomeevolution in angiosperms. The common presence of several copies of genes (and gene products) - and thus potential redundancy in the plant genome- might be a reaction to the complexity of the environment as plants perceiveit.

\section{The importance of individuality}

Theterm individuality is used to describe situations in which morphologically similar cells, tissues or plants show non-similar or uniqueresponses to signals. Commonly, individuality can be identified in situations in which development is'all-or-none'21. The cell or tissue does, or does not, respond to the inducing signal; flowering, abscission, germination, bud break and root formation are good examples. In these cases, an increasing strength of stimulus (light photoperiods, growth regulator concentrations) leads to a response from more of the population. The dose-response curvetherefore represents the different sensitivities of theindividuals of the population to thestimulus ${ }^{22}$.

Cells of the stomatal complex ${ }^{23}$, aleurone $^{24,25}$ and pericycle $e^{26,27}$ have all been observed as heterogeneous populations in a single tissue. When the concentration of a modifying stimulus such as auxin, gibberellin or abscisin is increased, progressively more cells respond (FIG.2). Each cell thereforehas its own sensing threshold and, when this is exceeded, a response is initiated. H owever, thereis also variation in thelag period before individual cellsrespond, and in the duration of the response $\mathrm{e}^{23,26}$. Individuality in regulation of thelac operon in bacterial populations was observed many years ago ${ }^{28}$. Partial expression of the lac operon represented simply the numbers of bacteria that had madethetransition.

Explanation of such individuality probably lies in certain stochastic processes during plant-cell development. The cytoplasm of a mature plant cell is little more than a few picolitres in volumeand contains about $20 \%$ protein. Depending on the cell type and the signalling pathway, the numbers of molecules in each cell concerned with signal transduction and the control of gene expression are estimated to range from single figures to under a thousand ${ }^{29}$. Predictions of cellular properties are usually based on the assumption that the cytoplasm is a homogeneous, relatively dilute solution, containing statistically largenumbers of molecules; cellular kinetics are assumed to rely on concentration and equilibrium constants to determineinteractions. In neither case is this truefor the cell.

How accurately, for example, can a cell control the amount or behaviour of regulatory proteins or transcription factors that number
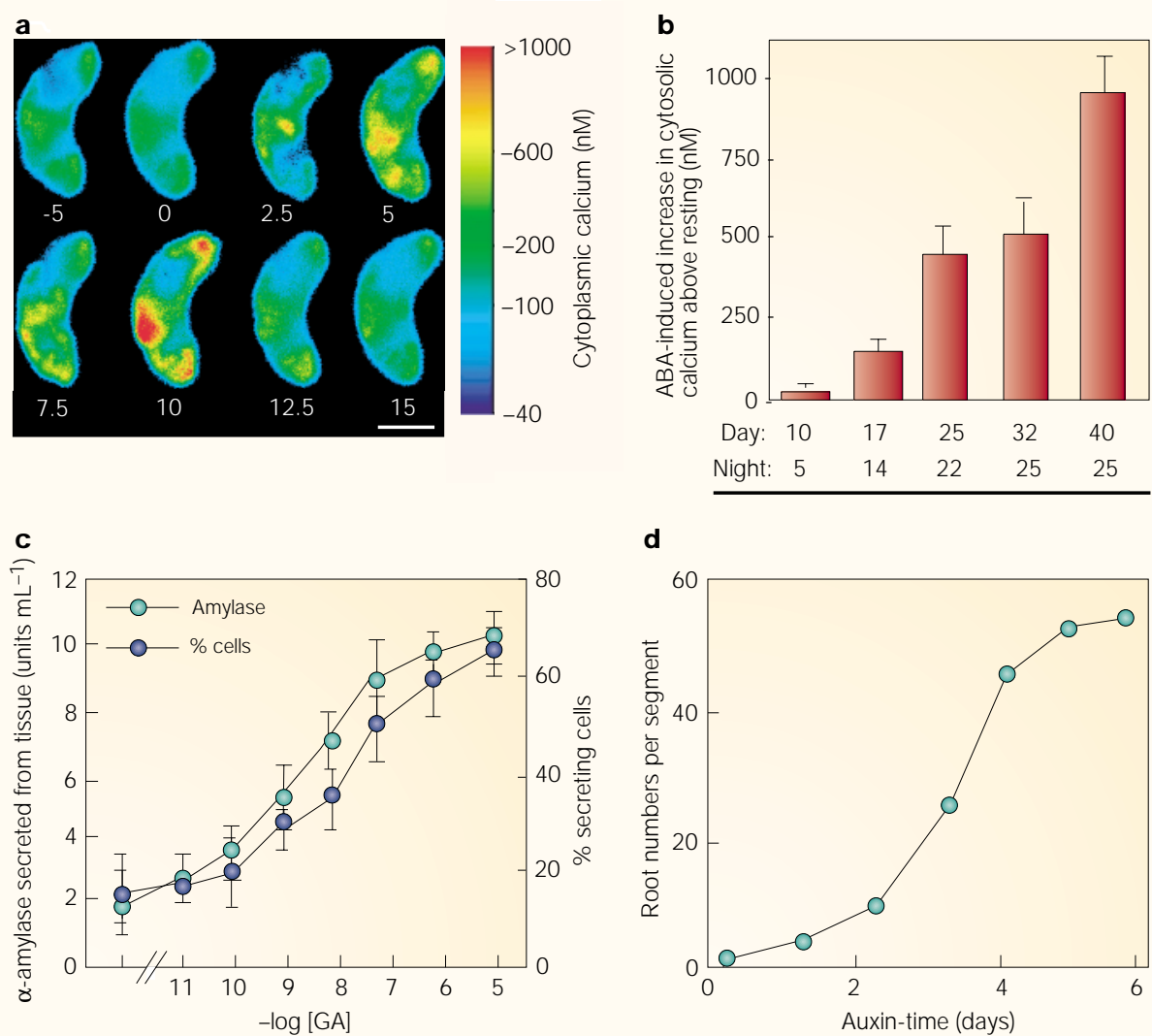

d

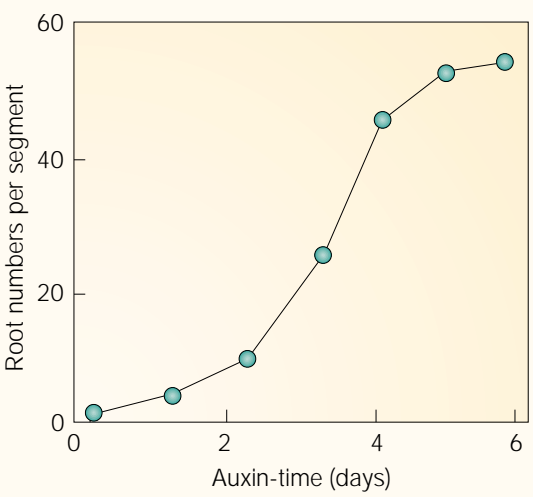

Figure 2 | Plant cell signalling systems show characteristics of cell-to-cell individuality, threshold phenomena and environmental entrainment. a |Cytosolic $\mathrm{Ca}^{2+}$ changes in stomatal guard cells of Arabidopsis thaliana treated with abscisic acid (ABA). $\mathrm{Ca}^{2+}$ levels were monitored by confocal ratio imaging of the $\mathrm{Ca}^{2+}$-sensitive ratiometric dye Indo-1 dextran microinjected into the cells. Note the spatial and temporal variability in the $\mathrm{Ca}{ }^{2+}$ increase induced by $\mathrm{ABA}$ within a single cell. Calcium levels are pseudocolour-coded according to the inset scale. Numbers reflect time after addition of 20-mM ABA. Scale bar represents $5 \mu \mathrm{m}$ (S.G., unpublished data). b | The precise kinetics of plant signalling systems can be environmentally determined. The maximal ABA-induced $\mathrm{Ca}^{2+}$ increase in guard cells of Commelina communis depends on the previous growth conditions of the plant. The lower the growth temperature, the less the guard cells seem to use a $\mathrm{Ca}^{2+}$-dependent ABA signalling system. (Data redrawn from REF 83.) c | Dose-response curve of $\alpha$-amylase secretion from barley aleurone induced in response to gibberellin (GA) shows threshold phenomena for plant-cell responses. The aleurone is a secretory tissue that responds to the growth regulator gibberellin by producing hydrolases as part of the reserve mobilization system that supports cereal grain germination. Note the dose response of the whole tissue reflects the recruitment of more cells with higher threshold for activation to the secreting population as the gibberellin levels are increased ${ }^{24,25}$. d | Root segments (Haplopappus ravenii) were exposed to auxin $\left(5 \times 10^{-7} \mathrm{M}\right)$ for the numbers of days shown (auxin-time) and then placed in auxin-free media for the remainder of the 6 day total incubation period when lateral roots were counted. As roots are formed by division from root pericycle cells, these data (redrawn from REF. 27) indicate substantive time variation in sensitivity to auxin. The first derivative of these data produces a bell-shaped curve indicating stochastic variation in time sensitivity to auxin among a supposedly uniform tissue ${ }^{27}$.

fewer than ten to a hundred? Can we comprehend regulation when only a few dozen moleculesareinvolved, and in cases where stochastic or chaotic events could be crucial in determining theoutcome? How will environmental variation during cell or tissue specification modify the partition or synthesis of such small numbers of proteinsat crucial cell cycles? Even when dealing with several thousand protein molecules, are cellular processes sufficiently accurate to ensure an identical number of copies between different cells? And thereareat least 10,000 cellular proteins.

It is at crucial stages of cell specification that individuality emerges. The adult plant originates with the first division of the zygote. Many tissuesin plantsoriginatefrom just one or a few cells. And particular cells within tissues such as leaf guard cells certainly originate from single cells. Variations in the small number of crucial transcription factorsat any of thesestages will ensure theindividuality that is subsequently observed.

Such epigenetic 'noise' could be consid- 


\section{Box 2 | Biological advantages to individuality}

Individuality al lows phenotypically plastic responses to the environment. Plants can adjust the numbers of branch roots to best fit the prevailing circumstances ${ }^{72}$. Variation in individual aleurone cells allows amylase production in the germinating cereal seedling to be adjusted according to variable germination circumstances ${ }^{24-26}$. Trees can optimize the number of leaves to a reduced water supply simply by abscising the excess ${ }^{73}$. In the case of leaf guard cells, subpopulations more sensitive than others to light, abscisic acid, water deficit, humidity or carbon dioxide, for example, allow the leaf to optimize water relation $s^{26}$ by using different combinations of the sub-populations of guard cells.

Individuality in signal transduction also allows plants to deal more effectively with herbivores and disease. The same herbivore signal causes different induced responses in different plants of the same species and in different tissues of the same individual ${ }^{74}$. Every leaf can assume a different phenotype owing to the expression of resistancegenes. And even though each step might betranscriptionally regulated, the net effect of the induced response might seem random, without detailed knowledge of the position, age, history and chemical environment of the effected tissue. This moving target, n-phenotype strategy ${ }^{74}$ is a crucial example of plant individuality and plasticity.

ered irrelevant, a biological nuisance, but plants probably engineer such variation because it allows a graded responsefrom the population of plants, tissues or cells and thus increases fitness (BOX 2). Clearly, individuality forms a basis for phenotypic plasticity in terms of numbers of roots, flowers or leaves. But during tissue specification, the crucial transcription factor numbers might instead ensure the production of a small population of mother cells with different potentialities. According to environmental conditions at the time, one or other mother cell could be cloned to produce the tissuemost relevant to prevailing circumstances.

\section{"Although there are many sites within the cell where signal integration and processing can occur ... the unusual properties of the plant-cell plasma membrane make it a prime candidate for the location of the 'cellular computer'."}

\section{Individuality in calcium signalling} Changesin cytosolic $\mathrm{Ca}^{2+}$ are recognized as ubiquitous regulators of cell function and providesome of the clearest indications of the individual behaviour of plant signalling molecules when viewed at the single-cell level. Calcium responses induced by thesamesignal are rarely identical between any two plant cells of the same type ${ }^{22,30,31}$. Such individuality probably results from the low numbers of channels and receptorsinvolved in $\mathrm{Ca}^{2+}$ entry.
This cell-specific behaviour suggests that the cell orchestrates the essential $\mathrm{Ca}^{2+}$ kinetics of thesignal necessary to elicit the appropriate response, rather than thereverse ${ }^{32}$.

However, a further unusual property of plant signalling systems is that signals susually inducethe synthesis of the proteins that are involved in mediating theresponse. Oneobvious exampleisthat increases in the levels of $\mathrm{Ca}^{2+}$ inducethe synthesis of calmodulin, but many others (phospholipases, calmodulin-like domain protein kinases, mitogen-activated protein kinases, resting levels of second messengers and so on) have been recorded ${ }^{33-35}$. One explanation is the construction of new signal-transduction equipment in each cell, designed to takeaccount of thenew circumstances after the first set of signals. As such, these changes in expression would represent a cellular 'memory' of the environmental history of the cell, perhaps providing a molecular explanation for how a plant can incorporate its growth history into its future developmental decisions. In addition, a form of cellular learning ${ }^{34}$ takes place because increased information flux through cytosolic $\mathrm{Ca}^{2+}$ should result. An alternative is that more cells might beslowly recruited into a signalling mode, so the answer lies in explanations from individuality. Whatever the functional basis for this signal-induced synthesis of signalling proteins, it seems an unusual and widespread feature of plant signalling systems worthy of further investigation.

\section{Principles of perception}

Occupied receptors are usually considered the start of any signal-transduction network, and our knowledge of plant receptors has advanced considerably over the past 5-10 years. Small families of receptors for red and bluelight, ethylene and brassinosteroids have been isolated ${ }^{32,36-38}$ (FIG. 3). Sugars, which can act as internal plant morphogens, might be sensed by hexokinase ${ }^{39}$. Receptor-likekinases are prominent in the Arabidopsis thaliana genome ${ }^{40}$ and, with their putativeligands, they are thought to mediate processes such as incompatible pollen-stigma interactions ${ }^{41}$ and themaintenance of meristem structure ${ }^{19}$.

Phytochrome, the red/far-red-light sensor, has some characteristics of a two-component-like phosphorylation system similar to those in bacteria, although it acts as a serine/threonine rather than histidine kinase $^{5,25}$. The blue-light sensors cryptochrome and NPH (non-phototropic), which use flavins or pterins as chromophores, might coupleinto redox system $s^{42,43}$. Ethylene is one of five main growth regulators, and its receptors (such asEth-1) have been characterized as histidine kinases similar to bacterial two-component signalling system $\mathrm{s}^{44}$. A candidate cytokinin receptor has al so recently been identified as a histidine-kinase-like protein ${ }^{45}$. A close relationship between auxin transport and perception has been predicted, and this may beclarified now that candidates for auxin receptors and auxin-transport proteins have emerged ${ }^{46,47}$. Despite such successes, however, we still lack specific candidate receptors for the growth regulators gibberellin and abscisin. But structure-activity relationships indicate that all of these growth substances might be sensed through proteinaceous receptors. N early all the receptors shown in FIG. 3 are located in the plasma membrane. Theexceptions - for example, phytochromeand cryptochrome- must be fixed to somespecific spatial cellular domain because cells can sense gradients of light. Sites near the plasma membrane, fixed perhaps to an attached cytoskeleton, have been suggested ${ }^{32}$.

The plasma membrane as a computer Perception of signals is, however, more complex than the limited families of receptors indicated abovemight suggest. For example, in the case of light, not only can red and blue light be easily distinguished, but plant cells can assess the total quantity of light received, the direction from which the light comes, the intensity during exposure, thetime (minutes to many hours) that light was available, and thetemporal order in which red or bluelight has been perceived ${ }^{48,49,50}$. It has been speculated that an unknown group of PAS/kinaseproteins revealed by the Arabidopsis genomeinitiative ${ }^{51}$ could be a new class of photoreceptors. H owever, it is likely that many of these complex light-perception events are donethrough interactions between the small number of receptorsalready identified. 
Thetiming, direction and quantity characteristics arealmost certainly shared in the perception of growth regulators, nitrate, water, gravity, temperatureand mechanical signals. Whatever the receptors for these latter signals, transduction mechanisms have to account for a complexity of perception not easily explained by single classes of receptor. Furthermore, as indicated earlier, it isnecessary to account for an ability to integrate many signals and to compute'intelligent' decisions.

Although there are many sites within the cell wheresignal integration and processing can occur, such as organelles, cytosol, cytoskeleton and endomembranes, the unusual properties of the plant-cell plasma membranemake it a primecandidatefor the location of the'cellular computer'. Probably 500-1,000 proteins and enzymes at very high density are embedded or attached to the plasma membrane ${ }^{11,52}$. These include receptors (FIG. 3), protein kinases ${ }^{53,54}$, ion channels $s^{55}$, microfilament anchorage and signal-transduction proteins involved in second-messen-
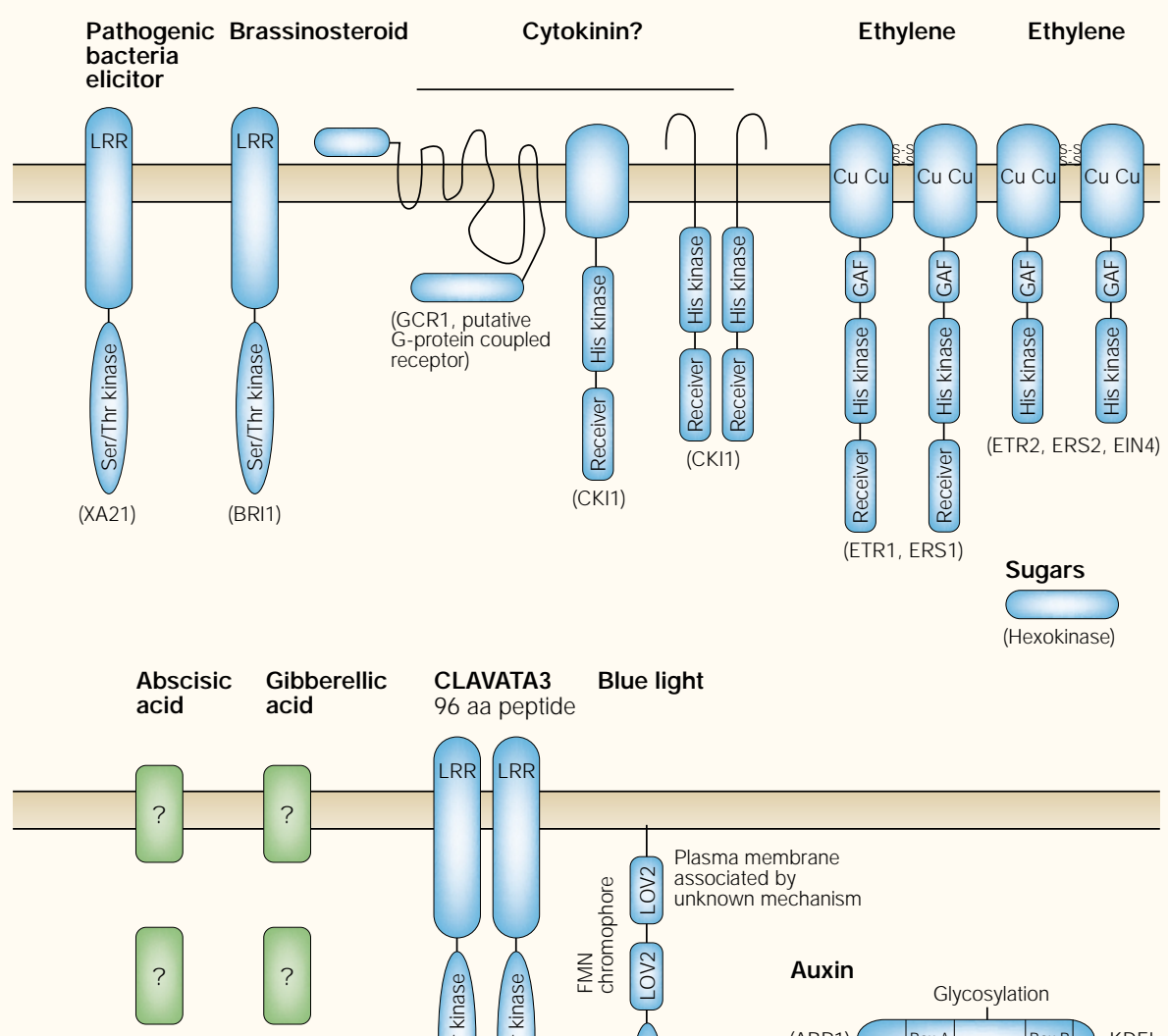

Red/far red light

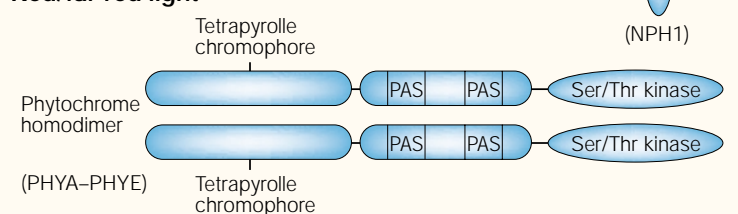

CLAVATA3 Blue light
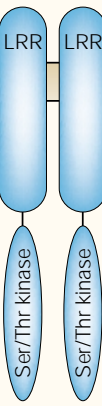

CLAVATA1)

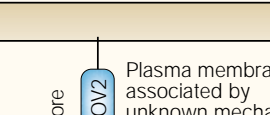

$\begin{array}{ccc}1 & \text { Plasma membrane } \\ \text { associated by } \\ \text { unknown mechanism }\end{array}$

$\sum_{4} \frac{1}{U}$
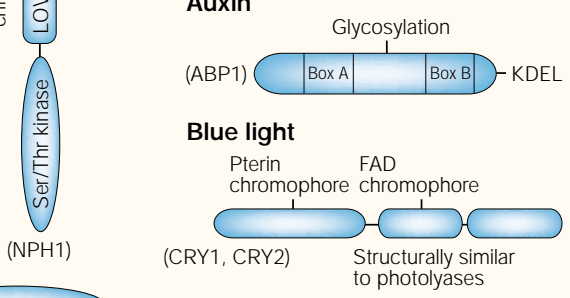

chromophore

Figure 3 | The domain structures of several known plant receptor proteins, putative receptors or components of putative perception complexes, and their respective ligands. His kinase, histidine protein kinase domain; KDEL, endoplasmic-reticulum retention sequence; LOV, light/oxidation/voltage sensor-like protein domain; LRR, leucine-rich-repeat motif; FMN, flavin mononucleotide; FAD, flavin adenine dinucleotide; PAS, carboxy-terminal structural PAS repeat domain; Receiver, domain homologous to bacterial two-component signalling system receiver proteins; Ser/Thr kinase, serine/threonine protein kinase domain; ? unknown protein. For more detailed discussion of the structure and function of these receptors and putative receptors see: phytochromes (PHYA-E) $)^{38} ;$ cryptochromes $(C R Y 1,2)^{42}$; auxin $(\mathrm{ABP} 1)^{47}$; phototropin (NPH1) ${ }^{43}$; hexokinase ${ }^{39}$; LRR protein kinases as receptors for brassinosteroids (BRI1) and pathogens (XA21) $)^{84}$; ethylene (ETR1) ${ }^{44}$; cytokinin (CRE1, CKI1, GCR1) ${ }^{45,85}$; CLAVATA1 ${ }^{86}$ (also see the review by Steven $E$. Clark on page 276 of this issue); and references therein. ger production ${ }^{32}$. Scaffold proteins on the cytoplasmic face of themembranesimilar to ankyrin are probably also present because ankyrin-binding regions in some plant proteins havebeen identified. The domain on the cytoplasmic surface is likely to be hydrophobic, with limited numbers of water molecules encouraging protein-protein interactions. Early electron microscope studies indicated that complexes of proteins were present and that the whole membrane was enormously differentiated ${ }^{56}$. Limited identification of these complexes has been made, although someare probably transient and formed only after signalling has commenced (BOX 3).

Current views on plasma membrane behaviour suggest a fluid mosaic structure ${ }^{52}$. But these models are often derived from motile animal cells and there are reasons (such as polarized cell growth and tissue morphology, sensing the direction and gradients of incoming signals, lack of cell mobility) that indicate that many functions in plant cells might be fixed rather than mobile. Even if large protein complexes are effectively free to move, diffusion will be extremely slow. The wall provides an obvious anchor for proteins, particularly for those that straddle themembrane ${ }^{52}$.

The plasma membrane is under turgor pressureand is compressed against thewall. M ovement of proteins will be hindered by wall constituents and thus membranefluidity will be reduced by the pressure. Changes in turgor (for example, from hypo-osmotic shock) or bending of the cell will concomitantly alter the conformation of structurally attached protein s by stretching or otherwise deforming the bilayer. Such treatments result in immediatetransients in cytosolic $\mathrm{Ca}^{2+}$ (REFS 57,58). Theimplication is that channel proteins areeither directly or indirectly anchored to the wall as the $\mathrm{Ca}^{2+}$ involved enters from outside thecell. Changes in wall-membrane protein interactions could provide therapid channel gating observed under these conditions.

Thelargenumbers of protein kinases and phosphatasesfound in cells present serious problems for fluid mosaic models. At least 1,000 protein kinases are present in the Arabidopsis genome $\mathrm{e}^{51}$ and the density at membrane surfaces is probably very high. For any signal to navigate, with fidelity, through the forest of protein kinases and phosphatases, requires severe spatial constraints on plasma membrane protein kinases to ensure specific modification of protein substrates ${ }^{32}$. Somekinases might be permanently tethered to scaffolds constructed around the plasma membrane and the associated cytoskeleton, but others might transiently 


\section{B ox 3 | Stable and transient protein complexes}

There are over 1,000 protein kinases in plant cells and, for a signal to navigate correctly its way through this morass of transduction proteins, spatial location is essential. Stable connections of protein kinases to the plasma membrane involve farnesylation, myristoylation or prenylation; less permanent ones involve autophosphorylation, phosphorylation of scaffold proteins, or localized high concentrations of activating second messengers. Simple, calcium-induced transduction complexes - such as prenylated calmodulin targeted to the plasma membrane $e^{67}$, or a membrane-associated calmodulin-like domain protein kinase (CDPK) regulating a membrane transporter ${ }^{54}$ - are probably dwarfed by semi-permanent structures such as those described in animal cells by caveolae and rafts ${ }^{75,76}$. These structures (transducons ${ }^{11}$ ) are nucleated around particular membrane lipids or even scaffold-like proteins, and contain many plant-cell transduction proteins that are involved in phosphoinositide production and phospholipid modification ${ }^{77,78}, \mathrm{Ca}^{2+}$-signalling proteins, calmodulin, kinases, water channels, nitric oxide synthase, anchorage proteins and some enzymes. The constituents of these transducons are dynamic, moving in and out of the complex after signalling.

Although researchers have barely begun to define these structures in plants, the Cop9 signalosome (an eight-subunit complex regulating de-etiolation, and controlled by phosphorylation ${ }^{79}$ ) is a clear case for a stable plant-transduction complex. Three kinds of less stable signalling complex - but nonetheless associated with the plasma membrane - have also been reported. And many more can be expected.

Complexes can form around pleckstrin homology (PH) domain $\mathrm{s}^{80}$ in plant cells, and about ten genes in the Arabidopsis thaliana genome contain a $\mathrm{PH}$-like domain, including protein kinases ${ }^{81}$. The $\mathrm{PH}$ domain binds to phospholipids, and aggregation is usually initiated by phosphorylation or autophosphorylation resulting from receptor occupation. The aggregate can ensure substrate activation or phosphorylation leading to the initiation of, for example, mitogen-activated protein kinase (M APK) cascades ${ }^{35}$. A second set of less stable complexes has been reported to form with CIAVATA, Rop GTPase, other regulatory proteins and M APK $s^{40}$. Finally, the 14-3-3 proteins are represented in plant cells by a family of about ten genes. Usually such proteins cross-link others after phosphorylation, and CDPK has been reported to activate 14-3-3 proteins, which are probably involved in controlling AT Pase activity within the plasma membrane ${ }^{82}$.

connect with their substrates only after specific bindingsites have been exposed.

Electrical properties

Although few plants use action potentials for communication, in thosethat do, the enzymatic and electrical properties of the plasma membraneallow summation, integration and computation of electrical properties; just as they do in nerve cells $s^{5,59,60}$. Like many other aspects of plant life, action potentials in plants areslow compared with those in animals. But even slower again, and lasting minutes, arethe very pronounced transient falls in membrane

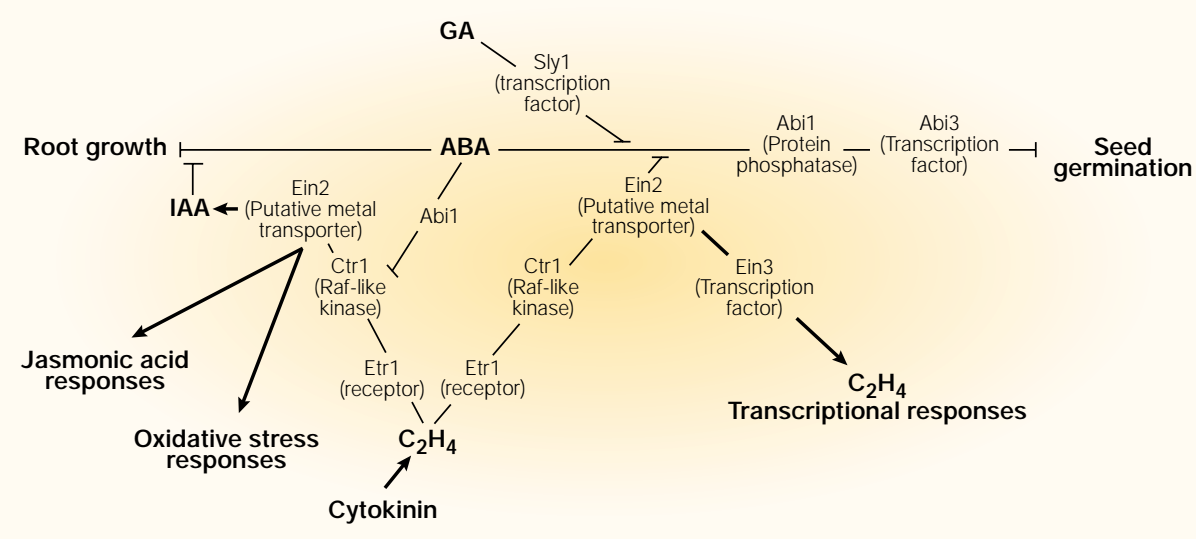

Figure 4 | Plants show extensive cross-talk and interactions between signalling systems. Recent genetic analysis of the physiological responses of mutants of Arabidopsis thaliana has uncovered possible molecular elements of a complex interacting network of control allowing growth regulators, such as auxin (IAA), cytokinin, ethylene $\left(\mathrm{C}_{2} \mathrm{H}_{4}\right)$, abscisic acid (ABA) and gibberellin (GA), to interact in the regulation of root growth, stress and defence responses (such as oxidative stress and jasmonic-acid responses), and seed germination ${ }^{87-89}$. Despite its complexity, this is a simplified view of the true regulatory interactions that occur in the plant cell. potential that might be regarded as a kind of pseudo action potential. Many plant-cell signals induce these changes in membrane potential; auxin, gravity, abscisic acid, blue light and red light are excellent examples ${ }^{5,50}$. These electrical changes are unlikely to be used for cell-cell communication. But the electrical changes will beas profound on the properties of the plasma membraneas those of the genuine action potential itself. Furthermore, a change in membrane potential should allow signal integration as observed for action potentials.

Much el ectrophysiological information indicates the presence of voltage-gated channels in the plant plasma membran ${ }^{61}$. As the membrane potential changes, the channel proteins undergo conformational changes that promoteopening (or closing) and subsequent altered ion flux. However, thereis no reason to think that channels are the only proteins to undergo electrically dependent structural change. On the cytoplasmic face of the plasma membrane, higher rates of ion flux will radically alter theionic strength, particularly near the mouth of channels; the availability of water will bechanged, modifying protein-protein interaction and protein complex status; electrical changes will modify thethreedimensional conformation of many proteins, exposing groups for phosphorylation/phosphatase action and alterations in surface charge might even alter membrane lipid mobilities.

We propose that one important result will beto modify receptor phosphorylation and diversify receptor behaviour. Phosphorylation al ters both conformation and function and can generateproteins with different activities according to sites and numbers of phosphorylated amino acids. A simple feedback loop is closed in which perception modifies subsequent perception. Thestructure of many protein complexes and channels might be altered for extended periods by phosphorylation. Mechanismsfor timing of the signal exposure, estimates of the quantity of signal arriving and for long-term modifications of plasma membrane function can therefore easily be constructed. In cases that there areno obvious receptor proteins (such as for water or nitrate), transporting proteins themselves (in this case, the water channels or nitratetransporters) might provide the necessary basisfor perception ${ }^{11,62}$.

Thesignificance of a change in membrane potential itself to signalling is supported by older observations, which showed that many organic chemicals, thiol (SH)-group reagents and respiratory inhibitors can break seed and bud dormancy, or induce root formation for 
example. The common property linking these chemicals is a demonstrated changein membrane potential2,63,64.

\section{Signal computation with attitude} If the plasma membraneis highly structured and activation of channels is localized, then a means to coordinate the behaviour of the membrane becomes necessary. Changes in $\mathrm{Ca}^{2+}$ fluxes across this membrane provideone example of how such coordination could be effected. The basis of $\mathrm{Ca}^{2+}$ signalling is the separation of different concentrations across a membrane, energized by $\mathrm{Ca}^{2+}$ ATPases. Upon signalling, channels open in the requisite membrane, allowing $\mathrm{Ca}^{2+}$ to move down its electrochemical potential gradient. Cytosolic $\mathrm{Ca}^{2+}$ has threeproperties that makeit ideal for plasma membranecoordination. Calcium is not a mobile ion in the cytoplasm ${ }^{65}$; $\mathrm{Ca}^{2+}$ signals move as waves that arethought to beconstrained to the cytoplasmic surface of the membrane ${ }^{33}$, and these waves are usually initiated at specific cellular sites ${ }^{57}$.

\section{"The same panoply of building blocks can be used in transduction between both plants and animals but, by changing their relationships and interactions, different properties will emerge."}

When plant cells are subjected to several signals, they seem able to access different sources of cytosolic $\mathrm{Ca}^{2+}$, producing a different response to each signal ${ }^{57}$. Single-cell imaging of $\mathrm{Ca}^{2+}$ changes in response to different signals confirms these observation $\mathrm{s}^{30}$. A highly structured arrangement of channels, $\mathrm{Ca}^{2+}$ stores and wave direction is implied. These waves might have complex fractal-likeforms. O nly certain discrete spatial regions of the plasma membrane may be activated by $\mathrm{Ca}^{2+}$ elevation ${ }^{5766}$ (FIG. 2). By varying the combinations of plasma membrane regions that are activated, considerable potential for the computation of signals emerges. Several important $\mathrm{Ca}^{2+}$-binding proteins, such as calmodulin $^{66,67}$ and CDPK ${ }^{53,54}$, are attached to the plasma membrane.

Evidencethat structural rearrangements of the plasma membraneresult from signalling can be deduced from an experimental separation of signals from the associated $\mathrm{Ca}^{2+}$ transients and physiological effects. Plant cells given a hyperosmotic shock ${ }^{58}$ or exposed to red light ${ }^{68}$ will normally express some transient increase in cytosolic $\mathrm{Ca}^{2+}$. H owever, if thesignal isimposed in the absence of extracellular $\mathrm{Ca}^{2+}$, no $\mathrm{Ca}^{2+}$ transient is observed. The physiological response and the $\mathrm{Ca}^{2+}$ transient are del ayed until $\mathrm{Ca}^{2+}$ is added back to thecells, when both progress normally. Some 'excited' stateis induced by theinitial signal; this lasts 20 minutes with hyperosmotic shock and up to 4 hours with red light.

\section{Future directions}

Fundamentally, lifeis organization. The cell is a product of the special properties that emergefrom thecomplex interactions and spatial structures between the many thousands of molecules and enzymes of which it is composed. The same panoply of building blocks can be used in transduction between both plants and animals but, by changing their relationships and interactions, different properties will emerge. The plasma membrane (perhapsmoreso in a plant cell than others) acts as a relatively permanent structure on which many kinds of transduction structure can bemade. This might represent part of the answer to the question posed in thePreface. Emphases on spatial relationships and cross-talk ${ }^{8}$ between signalling pathways seems to becrucial.

The completion of the sequencing of various plant genomes will provide us with a phenomenally rich array of candidate regulators of plant-cell function. The direction now must be to define which molecules interact with each other and wherethese interactions occur in vivo. Emerging technologies, such as green fluorescent protein fusions, live cell imaging of fluorescence resonance energy transfer and fluorescencelifetimeimaging ${ }^{31}$, are beginning to approach these questions in theonly setting where these interactions can really be determined - the intact, functioning cell. By this means, wewill slowly unravel the network of connections (FIG. 4) that provides unity to cellular and plant activities and that is undoubtedly present. The particular properties of the living cell are shared in some way or another through every constituent molecule, forming a highly integrated regulatory network. Equally, theenvironmental context, whether from outside the plant or from within, contributes to shaping how information is processed by each cell. In trying to understand signal transduction, we are doing no morethan trying to understand lifeitself.

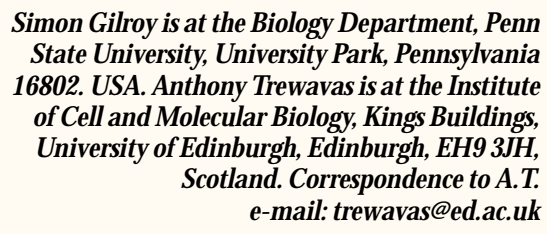

(2) Links

FURTHER INFORMATION Trewavas lab home page | Gilroy lab home page

ENCYCLOPEDIA OF LIFE SCIENCES Plant growth factors and receptors | Plant plasma membrane

1. Trewavas, A. J in Plasticity in Plants (eds I ennings, D. \& Trewavas, A. J.) Symp. Soc. Expt. Biol. Med. 40, 31-77 (1986).

2. Trewavas, A. J ., Sexton, R. \& Kelly, P. Polarity calcium and abscission: molecular bases for developmental plasticity in plants. J . Embryol. Exp. Morphol. 83, S179-S195 (1984).

3. Smith, H. \& Whitlam, G. C. The shade avoidance syndrome: multiple responses mediated by multiple phytochromes. Plant Cell Environ. 20, 840-844 (1997).

Wijensinghe, D. K. \& Hutchings, M. J. The effects of environmental heterogeneity on the performance of Glechoma: the interactions between patch scale and patch contrast. J. Ecol. 87, 860-872 (1999).

5. Trewavas, A. J. in Biochemistry and Molecular Biology of Plants (eds Buchanan, R. B., Gruissem, W. \&J ones, R. L.) 930-988 (Am. Soc. of Plant Physiologists, Rockville Maryland, 2000).

6. Jenkins, G. I. Signal transduction networks and the integration of responses to environmental stimuli. Adv. Bot. Res. 29, 54-74 (1999).

7. Novoplansky, A. Developmental responses of Portulaca seedlings to conflicting spectral signals. Oecologia $\mathbf{8 8}$ 138-140 (1991).

8. Novoplansky, A., Cohen, D. \& Sachs, T. Ecological implications of correlative inhibition between plant shoots. Oecologia 82, 490-493 (1990).

9. Kelly, C. E. Resource choice in Cuscuta europea. Proc. Natl Acad. Sci. USA 89, 12194-12197 (1992)

10. Kelly, C. K. Plant foraging: a marginal value model and coiling response in Cuscuta subinclusa. Ecology 71 , 1916-1925 (1990).

11. Gilroy, S. \& Trewavas, A. J . in The Plant Plasma Membrane (eds Larsson, C. \& Moller, I. M.) 203-233 (Springer, Berlin, 1990)

12. Trewavas, A. J \& Knight, M. R. Calcium, mechanical signalling and plant form. Plant Mol. Biol. 26, 1329-1341 (1994).

13. Green, P. B. Expression of pattern in plants: combining molecular and calculus-based biophysical paradigms. Am. J. Bot. 86, 1059-1076 (1999).

14. Fleming, A. J., Caderas, D., Wehrli, E., McQueen-Mason, S. \& Kuhlemeier, C. Analysis of expansin-induced morphogenesis on the apical meristem of tomato. Planta 208, 166-174 (1999)

15. Cosgrove, D. J. New genes and new biological roles for expansins. Curr. Opin. Plant Biol. 3, 73-78 (2000).

16. Knight, M. R., Knight, H. \& Watkins, N. J. Calcium and the generation of plant form. Phil. Trans. R. Soc. Lond. B 350, 83-86 (1995).

17. Firn, R. \& Digby, J. Solving the puzzle of gravitropism has a lost piece been found? Planta 203, S159-S163 (1997).

18. Sultan, S. E. Phenotypic plasticity for plant development function and life history. Trends Plant Sci. 5, 537-542 (2000).

19. Brand, U., Fletcher, J . C., Hobe, M., Meyerowitz, E. M. \& Simon, R. Dependence of stem cell fate in Arabidopsis on a feedback loop regulated by CLV3 activity. Science 289, 617-619 (2000).

20. School, $\mathrm{H}$. et al. The stem cell population of Arabidopsis shoot meristem is maintained by a regulatory loop shoot meristem is maintained by a regulatory loop 635-644 (2000).

21. Trewavas, A. J . in Plant Responses to Environmental Stresses (ed. Lerner, H. R.) 27-42 (Marcel Dekker, New 


\section{PERS PE C T IVES}

York, 1999)

22. Trewavas, A. J. How do plant growth substances work? (II). Plant Cell Environ. 14, 1-12 (1991).

23. Mott, K. A. \& Buckley, T. N. Patchy stomata conductance emergent collective behaviour. Trends Plant Sci. 5, 258-262 (2000).

24. Hillmer, S., Gilroy, S. \&J ones, R. L. Visualising enzyme secretion from individual barley protoplasts. Plant Physiol. 102, 279-286 (1993).

25. Ritchie, S., McCubbin, A., Ambrose, G., Kao, T.-H. \& Gilroy, $\mathrm{S}$. The sensitivity of barley aleurone tissue to gibberellin is heterogeneous and may be spatially determined. Plant Physiol. 120, 361-370 (1999).

26. Bradford, K. J. \& Trewavas, A. J . Sensitivity thresholds and variable time scales in plant hormone action. Plant Physiol. 105, 1029-1036 (1994).

27. Blakeley, L. M., Rodaway, S. J ., Hollen, L. B. \& Croker, S. G. Control and kinetics of branch root formation in cultured root segments of Haplopappus ravenii. Plant Physiol. 50, 35-42 (1972)

28. Novick, A. \& Weiner, M. Enzyme induction as an all or none phenomenon. Proc. Natl Acad. Sci. USA $\mathbf{4 3}$ 553-566 (1957).

29. McAdams, H. H. \& Arkin, A. Genetic regulation at the nanomolar scale. Trends Genet. 15, 65-69 (1999).

30. Gilroy, S., Fricker, M., Read, N. \& Trewavas, A. J . Role of calcium in signal transduction of Commelina guard cells. Plant Cell 3, 333-344 (1991)

31. Blancaflor, E. B. \& Gilroy, S. Plant cell biology in the new millennium: new tools and new insights. Am. J . Bot. 87, $1547-1560(2000)$

32. Trewavas, A. J \& \& Malho, R. Perception and transduction: the origin of the phenotype. Plant Cell 9, 1181-1195 (1997).

33. Trewavas, A. J. Le calcium c'est la vie. Calcium makes waves. Plant Physiol. 120, 1-6 (1999).

34. Trewavas, A. J. How plants learn. Proc. Natl Acad. Sci USA 96, 4216-4218 (1999).

35. Meskienne, I. \& Hirt, H. MAP kinase pathways: molecular plug and play chips for the cell. Plant Mol. Biol. 42, 791-806 (2000).

36. McCarty, D. R. \& Chory, J . Conservation and innovation in plant signalling pathways. Cell 103, 201-209 (2000).

37. He, Z. et al. Perception of brassinosteroids by the extracellular domain of the receptor kinase BRI1. Science 288, 2360-2361 (2000).

38. Genick, U. K. \& Chory, J. Red light sensing in plants. Curr. Biol. 10, R651-R654 (2000).

39. Smeekens, S. Sugar-induced signal transduction in plants. Annu. Rev. Plant Physiol. Plant Mol. Biol. 51 49-81 (2000).

40. Torii, K. U. Receptor kinase activation and signal transduction in plants: an emerging picture. Curr. Opin Plant Biol. 3, 361-367 (2000).

41. Schopfer, C., Nasrallah, M. \& Nasrallah, J. The male determinant of self incompatability in Brassica. Science 286, 1697-1700 (1999).

42. Cashmore, A. R., J arillo, J . A., Wu, Y.-J \& \& Liu, D. Cryptochromes: blue light receptors for plants and animals. Science 284, 760-765 (1999).

43. Christie, J. M., Salomon, I., Nozue, K., Wada, M. \& Briggs, W. R. LOV (light, oxygen, or voltage) domains of the blue-light photoreceptor phototropin (nph1): binding sites for the chromophore flavin mononucleotide. Proc. Natl Acad. Sci. USA 96, 8779-8783 (2000).

44. Stepanova, A. N. \& Ecker, J . R. Ethylene signalling from mutants to molecules. Curr. Opin. Plant Biol. 3, 353-360 (2000)

45. Inoue, $T$. et al. Identification of CRE1 as a cytokinin receptor from Arabidopsis. Nature 409, 1060-1063 (2001)
46. Galwieler, L. et al. Regulation of polar auxin transport by AtPIN1 in Arabidopsis vascular tissue. Science 282 2226-2230 (1998).

47. J ones, A. M. et al. ABP 1: auxin-dependent cell expansion mediated by overexpressed auxin-binding protein 1 . Science 282, 1114-1117 (1999).

48. Salisbury, F. B. \& Ross, C. W. Plant Physiology 4th edn (Wadsworth, California, 1992).

49. Baum, G., Long, J., J enkins, G. \& Trewavas, A. J . Stimulation of the blue light receptor NPH1 causes a transient increase in cytosolic calcium. Proc. Natl Acad. Sci. USA 98, 13554-13559 (1999).

50. Taiz, L. \& Zeiger, E. Plant Physiology 2nd edn (Sinauer Associates, Massachusetts, 1998).

51. Kaul, B. et al. Analysis of the genome sequence of the flowering plant Arabidopsis thaliana. Nature $\mathbf{4 0 8}$ 796-815 (2000).

52. Staehelin, L. A. \& Newcomb, E. H. in Biochemistry and Molecular Biology of Plants (eds Buchannan, R. B., Gruissem, W. \& J ones, R. L.) 2-50 (Am. Soc. of Plant Physiologists, Rockville, Maryland, 2000).

53. Harmon, A., Gribskov, M. \& Harper, J. F. CDPK's, a kinase for every signal. Trends Plant Sci. 5, 154-159 (2000)

54. Satterlee, J. S. \& Sussman, M. R. Unusual membraneassociated protein kinases in higher plants. J. Memb. Biol. 164, 205-213 (1998)

55. Hirsch, R. E., Lewis, B. D., Spalding, E. P. \& Sussman, M. R. A role for the AKT1 potassium channel in plant nutrition. Science 280, 918-921 (1998).

56. Volkmann, D. The plasma membrane of growing root hairs is composed of zones of local differentiation. Plant 162, 392-403 (1984).

57. Malho, R., Moutinho, A. Van der Luit, A. \& Trewavas, A. J S Satial characteristics of calcium signalling: the calcium wave as a basic unit in plant cell signaling. Phil. Trans. R. Soc. Lond. B 353, 1463-1473 (1998).

58. Takahashi, K., Isobe, M., Knight, M. R., Trewavas, A. J.\& Muto, $S$. Hypoosmotic shock induces increases in cytosolic $\mathrm{Ca}^{2+}$ in tobacco suspension culture cells. Plant Physiol. 113, 587-594 (1997).

59. Alberts, B. et al. Molecular Biology of the Cell (Garland, New York, 1989).

60. Bose, J. C. Plant Response as Means of Physiological Investigation (Longmans and Co., London, 1906).

61. Sanders, D. \& Bethke, P. in Biochemistry and Molecula Biology of Plants (eds Buchanan, B. B., Gruissem, W. \& J ones, R. L.) 110-160 (Am. Soc. of Plant Physiologists, Rockville, Maryland, 2000).

62. Zhang, H. \& Forde, B. G. An Arabidopsis MADS box gene that controls nitrate induced changes in root architecture. Science 279, 407-409 (1998).

63. Trewavas, A. J. Growth substances in context: a decad of sensitivity. Biochem. Soc. Trans 20, 102-108 (1991).

64. Trewavas, A. J. in The Molecular Biology of Plant Development (eds Smith, H. \& Grierson, D.) 8-28 (Blackwell Scientific, Oxford, 1982).

65. Hodgkin, A. L. \& Keynes, R. D. Movements of labelled calcium in giant squid axons. J. Physiol. 138, 253-281 (1957).

66. Zielinski, R. E. Calmodulin and calmodulin binding proteins in plants. Annu. Rev. Plant Physiol. Plant Mol. Biol. 49, 697-725 (1998)

67. Rodriguez-Concepcion, M., Yalovsky, S., Zik, M., Fromm, H. \& Gruissem, W. The prenylation status of a novel plant calmodulin directs plasma membrane or nuclear localisation of the protein. EMBO J . 18, 1996-2007 (1999).

68. Viner, N., Whitlam, G. \& Smith, H. Calcium and phytochrome control of leaf unrolling in dark grown barley seedings. Planta 175, 209-213 (1988).
69. J affe, L. F. Localization in the developing Fucus egg and the general role of localizing currents. Adv. Morphogen. 7, 295-328 (1968)

70. Kropf, D. L. Induction of polarity in fucoid zygotes. Plant Cell 9, 1011-1020 (1997)

71. Hader, D.-P. \& Hemmersbacj, R. Graviperception and graviorientation in flagellates. Planta 203, S7-S10 (1997).

72. Zhang, H., J ennings, A., Barlow, P. W. \& Forde, B. G. Dual pathways for regulation of root branching by nitrate. Proc. Natl Acad. Sci. USA 96, 6529-6534 (1999).

73. Addicott, F. T. Abscission (Univ. California Press, London, 1982).

74. Karban, R. \& Baldwin, I. T. Induced Responses to Herbivory (Univ. Chicago Press, Chicago, 1997).

75. Brown, D. A. \& London, E. Functions of lipid rafts in biological membranes. Annu. Rev. Cell Dev. Biol. 14, 111-136 (1998).

76. Anderson, R. G. W. The caveolae membrane system. Annu. Rev. Biochem. 67, 199-225 (1998).

77. Munnik, T. et al. Hyperosmotic stress stimulates phospholipase $D$ activity and elevates the levels of phosphatidic acid and diacylglycerol pyrophosphate. Plant J . 22, 147-154 (2000).

78. Stevenson, J. M., Perera, I. Y., Heilmann, I., Persson, S $\&$ Boss, W. F. Inositol signalling and plant growth. Trends Plant Sci. 5, 252-258 (2000).

79. Karniol, B. \& Chamovitz, D. A. The COP 9 signalosome: from the light signalling to general developmental regulation and back. Curr. Opin. Plant Biol. 3, 387-393 (2000)

80. Blomberg, N., Baraldi, E., Nilges, M. \& Saraste, M. The $\mathrm{PH}$ superfold: a structural scaffold for multiple functions. Trends Biochem. Sci. 24, 441-445 (1999).

81. Deak, M., Casamayor, A., Currie, R. A., Downes, P. \& Alessi, D. R. Characterisation of a plant phosphoinositide-dependent protein kinase- 1 homologue which contains a pleckstrin homology domain. FEBS Lett. 451, 220-226 (1999).

82. Roberts, M. R. Regulatory 14-3-3-protein/protein interactions in plant cells. Curr. Opin. Plant Biol. 3, 400-405 (2000).

83. Allan, A. C., Fricker, M. D., Ward, J . L., Beale, M. H. \& Trewavas, A. J . Two transduction pathways mediate rapid effects of abscisic acid in Commelina guard cells. Plant Cell 6, 1319-1328 (1994)

84. Zuhua, H. et al. Perception of brassinosteroids by the extracellular domain of the receptor kinase BRII. Science 288, 2360-2363 (2000).

85. Estelle, M. Cytokinin action: two receptors better than one? Curr. Biol. 8, R539-R541 (1998).

86. Trotochaud, A. E., J eong, S. \& Clark, S. E. CLAVATA3, a multimeric ligand for the CLAVATA1 receptor-kinase. Science 289, 613-617 (2000)

87. Alonso, J. M., Hirayama, T., Roman, G., Nourizadeh, S. $\&$ Ecker, J . R. EIN2, a bifunctional transducer of ethylene and stress responses in Arabidopsis. Science 284, 2148-2152 (1999)

88. Beaudoin, N., Serizet, C., Gosti, F. \& Giraudat, J. Interactions between abscisic acid and ethylen signaling cascades. Plant Cell 12, 1103-1116 (2000)

89. Ghassemian, M. et al. Regulation of abscisic acid signalling by the ethylene response pathway in Arabidopsis. Plant Cell 12, 1117-1126 (2000)

Acknowledgements

The authors would like to thank Sian Ritchie for critical reading of the manuscript at a late stage in its construction. We also gratefully acknowledge the support of the USDA, NSF and NASA (S.G.) and BBSRC and Human Frontier Science Programme Organisation (A.T.).

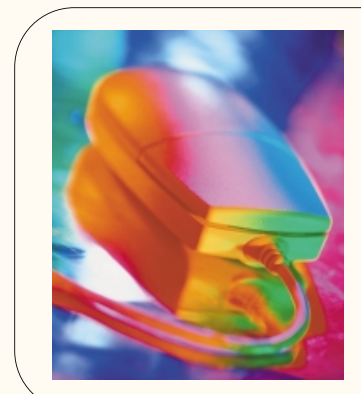

(w) Take a look online

Online, all Nature Reviews articles are enhanced with hyperlinks, including the following:

- References are linked to PubM ed abstracts.

-Geneand protein names, inherited diseases and protein domains are linked to public-domain databases such as LocusLink, Flybase, SGD, OMIM and InterPro.

- Links to other related online resources are provided.

-Web watch articles are linked to the resources discussed in the text. 